\section{Surgical Review: International Journal of Surgery, Trauma and Orthopedics}

2020 Volume 6 Number 2 March-April

\title{
Evaluation of factors determining the functional outcome of DHS in trochanteric fractures
}

\author{
Deshpande S. ${ }^{1}$, R Agrawal 5. ${ }^{2 *}$ \\ DOI: https://doi.org/10.17511/ijoso.2020.i02.03 \\ 1 Santosh Deshpande, Assistant Professor, Department of Orthopaedics, Ashwini Rural Medical College, Hospital and Research Centre, \\ Kumbhari, Maharashtra, India. \\ 2* Saurabh R Agrawal, Consultant, Agrawal Nursing Home, Solapur, Maharashtra, India.
}

\begin{abstract}
Background: In spite of improvement and modification for intertrochanteric fracture in the conservative line of treatment the ideal anatomical and functional result could not be achieved.Until now mentioned factors posteromedial support communition has been considered to bea major prognostic factor in the determination of the functional outcome. Current literature almost neglects other important potential prognostic factor i.e. lateral trochanteric wall fracture. The current study has aimed at studying Assessment of functional outcomes of Dynamic Hip screw fixation in intertrochanteric fracture Evans 3 and 4 types. Method: 126 cases were registered in the study out of which 64 cases of Trochanteric fractures which were admitted in the Orthopaedic wards and treated by internal fixation using standard Dynamic Hip Screw (DHS) were included in the study. Preoperative assessment of fracture geometry was done using Evan's classification. Result: Age of patients ranged from 22 years to 88 years, with the average being 55 yrs. the anatomical reduction was achieved in $82.5 \%$ of group A with intact lateral trochanteric wall whereas it was achieved in only $33 \%$ of the other group. Average impaction in group A was found to be $5.5 \mathrm{~mm}$ and average impaction in group B was $14 \mathrm{~mm}$. $85 \%$ of group A had functional outcome excellent to good whereas in $66 \%$ of group B it was fair to poor. Conclusion: Intact lateral trochanteric wall helps in achieving anatomical reduction, imparts inherent stability and prevents excessive collapse, limb shortening and sliding of the screw. Thus it helps in achieving good functional outcome making lateral trochanteric wall fracture good predictor of functional outcome.
\end{abstract}

Keywords: Trochanteric fracture, Dynamic Hip Screw (DHS), Evan's classification, Functional outcome

Corresponding Author

Saurabh R Agrawal, Consultant, Agrawal Nursing Home, Solapur, Maharashtra, India. Email: santosh_1010@rediffmail.com

\section{How to Cite this Article}

Deshpande S, Agrawal SR. Evaluation of factors determining the functional outcome of DHS in trochanteric fractures. Surgical Review Int J Surg Trauma Orthoped. 2020;6(2):79-86.

Available From

https://surgical.medresearch.in/index.php/ijoso/artic le/view/167
To Browse

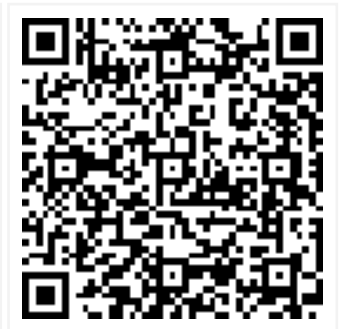

Manuscript Received 05-03-2020

Conflict of Interest No

C 2020 by Santosh Deshpar This is an Open Acce
Review Round 1 15-03-2020

Review Round 2
20-03-2020
Ethical Approval
yes

Review Round 2 yes
Review Round 3

Plagiarism X-checker $14 \%$
Accepted 26-03-2020

Note 


\section{Introduction}

The rapidly increasing number of hip fractures is posing one of the most severe Orthopaedic challenges in the new millennium. Intertrochanteric fractures of the femur once considered essentially a disorder of the elderly, are now equally common in young adults due to increased incidence of high energy trauma.

The overall increase in the incidence of intertrochanteric fracture can be attributed to two factors, one, increased life expectancy which increases the aged population, secondly high energy trauma which victimizes more number of young adults.Due to these reasons, both developing and developed countries are facing a sort of epidemic of intertrochanteric fractures.

Therefore, renewed attention should be paid to evaluate and improve the performance and longevity of Orthopaedic interventions aimed at treating intertrochanteric fractures.

The challenge the Orthopaedic surgeon faces lies in combining union in a good position with minimal morbidity, maximum comfort to the patient, early mobilization, decreased complication rate and the greatest economy of hospital beds,

Not much attention was paid to intertrochanteric fractures till 19th century and the mortality rate of intertrochanteric fracture was about $80 \%$, those who survived remained morbid due to bedsores, cystitis, joint stiffness deep vein thrombosis, hypostatic pneumonia, shortening and Coxa vara.

The treatment of intertrochanteric fractures has also passed through several stages, initially, theses fractures were treated conservatively by means of external splintage, skin traction, skeletal traction and balanced Russell traction.

In spite of improvement and modification in the conservative line of treatment, the ideal anatomical and functional result could not be achieved. Prolonged immobilization in bed was another important threat to the life of elderly patients. The problem is not of the union but of complications arising out of immobilization in bed till fractures heal.

Also in the young age group where high-energy trauma is often the culprit mode, the anatomy is distorted to the extent that, generally conservative treatment finds no scope.
The history of the treatment of intertrochanteric fractures has been of changes, modification and evaluation. The radical concept of operative management of intertrochanteric fractures has got new thinking in the last four decades. Improvement in theatre techniques, the evolution of newer strong and inert metal for implants, improved devices and techniques for fixation, advancements in radiology and the application of biomechanical principles to fixation has contributed to increased incidence of operative management of intertrochanteric fracture and reduced the value of conservative treatment due to complication associated with it.

Several methods of internal fixation were advocated in the treatment of intertrochanteric fractures, like fixed angle blade-plate by Jewett[1], variable angle nail plate by McLaughlin [2], which facilitated early painless weight-bearing and compression at the fracture site, especially unstable ones.

Schumplick Jantzen [3] described the sliding screw plate, which was modified by Massie and finally evolved into the present-day Richard compression screw system as described by MulthollandandGunnn[4]. Though internal fixation was logically the best way to restore stability and mobility, early attempts met with failure because of a high risk of infection and high mortality caused by surgical trauma on debilitated patients.

Sliding hip screw system (Dynamic Hip Screw) has proved to be the gold standard for the treatment of intertrochanteric fractures. Still, with all the qualities of an ideal implant DHS exhibits moderate failure rate.

Until now along with factors posteromedial support communition has been considered to bea major prognostic factor in the determination of the functional outcome. Current literature almost neglects other important potential prognostic factor i.e. lateral trochanteric wall fracture.

The current study has aimed at studying Assessment of functional outcomes of Dynamic Hip screw fixation in intertrochanteric fracture Evans 3 and 4 types after elimination of above-confounding factors.Sothe study was designed to find such relation and establish intertrochanteric fracture as an important prognostic factor along with other factors already mentioned in literature.

Objectives:Assessment of functional outcomes of Dynamic Hip screw fixation in intertrochanteric fracture Evans 3 and 4 types. 


\section{Material and Methods}

This prospective study was conducted in the Department of Orthopaedics, ARMCH and RC, Kumbhari from June 2016 to September 2018.

126 cases were registered in the study out of which 64 cases of Trochanteric fractures which were admitted in the Orthopaedic wards and treated by internal fixation using standard Dynamic Hip Screw (DHS) were included in the study.

These cases were selected on the basis ofthe following criterion.

01. Cases with trochanteric fractures who fit into any of the five grades of Evan's classification of trochanteric fractures.

02. Closed trochanteric fractures in patients 50 years or above were included

03. Pathological trochanteric fractures were excluded as their functional results differ

04. Patient with associated lower limb injuries, vertebral column injuries and incompletely recovered surgical illness were excluded from the study group, as they act as confounding factors.

\section{Selection of Cases for Post Op Follow Up}

01 . Those cases having a post-op neck-shaft angle between 130 to 140 degreeswere selected for follow up.

02. Those cases having TAD index less than $25 \mathrm{~mm}$ were selected for follow up

03. Those cases in which bone grafting was done were excluded from the study.

04. Those cases which were having the post-op complication of infection were excluded from the study.

Preoperative assessment of fracture geometry was done using Evan's classification. Intraoperatively pattern of reduction achieved was seen on Anteroposterior and Lateral projections by the image intensifier.

Using a TAD index assessment of Screw placement was done in the postoperative period. Neck shaft angle measured on immediate post-op $\mathrm{x}$-ray with the help of Goniometer.

During 1st follow up (2 weeks post-op), 2nd follow up (4 weeks post-op), 3rd follow up ( 3 months postop) and 4th follow up plain radiographs (true AP and
True lateral hip with thigh) were obtained to look for signs of union and impaction.

Functional results were evaluated after a period of 6 months postoperatively using new criteria devised from Harris hip score taking into consideration the needs of Indian patients( Modified Harris Hip Score).

\section{Grading of Fracture pattern}

Done using Evan's classification

Type I:Undisplaced 2-fragment fracture

Type II:Displaced 2-fragment fracture

Type III:3-fragment fracture without posterolateral support, owing to the displacement of greater trochanter fragment

Type IV:3-fragment fracture without medial support, owing to displaced lesser trochanter or femoral arch fragment

Type V:4-fragment fracture without posterolateral and medial support (the combination of Type III and Type IV)

\section{Cases were divided into two groups}

01. Group A (Stable Group) -It consisted of all cases with fracture pattern in which lateral trochanteric wall was intact. This group consists of Evan's grades I, II and IV.

02. Group B(Unstable Group) - It consisted of all cases with fracture pattern in which lateral trochanteric wall was broken. This group consists of Evan's grades III and V.

\section{Preoperative Management}

- A detailed history of selected cases, especially regarding the mode of trauma, pre-operative medical and associated illness, ambulatory status, activities of daily living before the trauma, was recorded.

- X-rays of the affected hip - True AP View and True Lateral View

- Depending upon the age and pattern of fracture as per $\mathrm{x}$-ray, above knee skin traction or upper tibial Steinmann pin, skeletal traction in Thomas splint was applied.

Preoperative Investigations: $\mathrm{Hb} \%, \mathrm{TC}, \mathrm{DC}, \mathrm{ESR}$, Blood urea and sugar, ECG if age more than 30 years, Chest $\mathrm{x}$-ray if age more than 60 yrs

Operative Management- Majority of the cases were operated under spinal anaesthesia on the 
Fracture table in supine position under image intensifier control. Prophylactic antibiotics were used 30 minutes before surgery (third-generation IV cephalosporin).

Primary Bone grafting was done in cases where posteromedial cortical contact was not achieved after reduction and fixation. Interfragmentary screw fixation was done wherever needed.

The current study followed the standard technique for fixation of DHS as recommended by $A O$.

Dynamic hip screw fixation technique: Patient is positioned supine on the fracture table with a radiolucent, padded counter traction post placed between the patient's legs at the perineal area. The uninjured leg is abducted and flexed at the hip joint and kept held in a well leg holder.

Alternatively, the uninjured leg can be held in wide abduction by a boot or footplate attached to one of the leg extensions of the fracture table. The injured leg is held by a footplate or boot attached to the other leg extension of the fracture table.

Both these positions allow the use of C-arm image intensifier positioned between patients leg to obtain AP and lateral images while keeping the C-arm on the non-sterile side.

The skin over the hip is prepared by a soap scrub and antiseptic solution. The lateral aspect of the hip joint is squared off from iliac crest to the distal thigh with towels and drapes, taking care not to place the towel clips so that they get superimposed over the fracture site on subsequent imaging.

Closed reduction of fracture is performed. Generally, trochanteric fractures can be reduced in neutral or slight internal rotation. Careful adjustment of traction is done to attain reduction avoiding too much traction, which can cause valgus over reduction.

The reduction is checked on both AP and Lateral images using image intensifier, paying special attention to cortical contact medially and posteriorly.

Exposure is done through a lateral approach from greater trochanter extending distally. The length of exposure depends upon the length of the implant used.
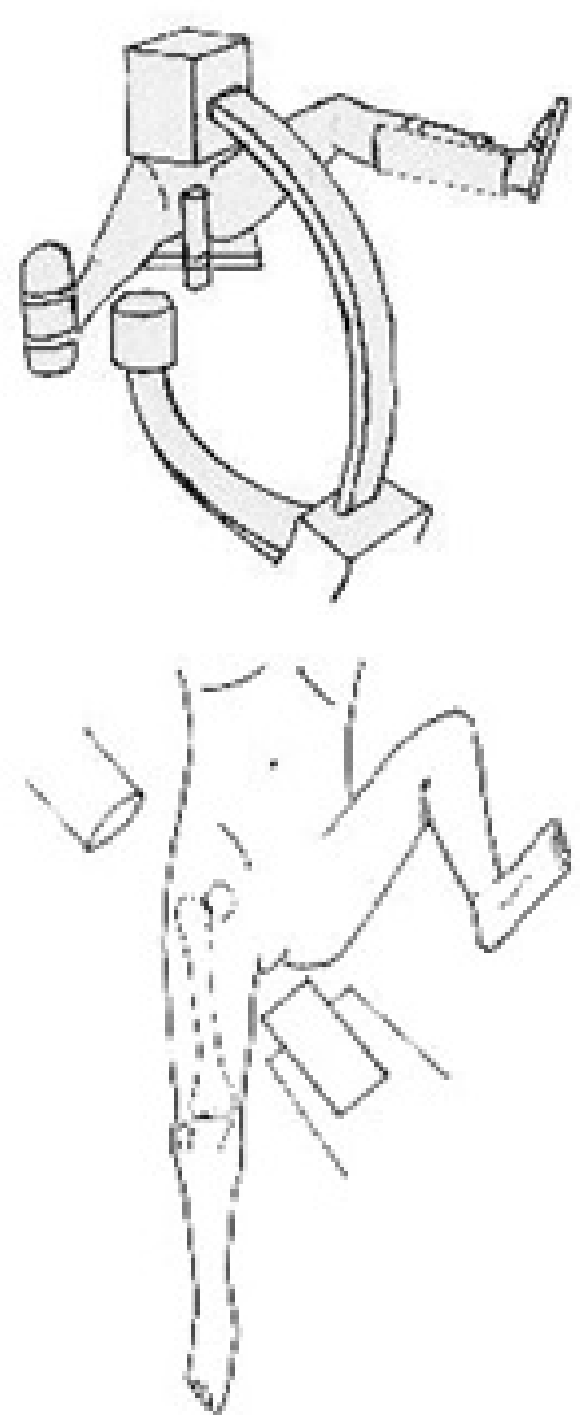

Fig-1: The correct position for obtaining AP and Lateral images using image intensifier

\section{Post Operative Management}

01. Intravenous antibiotics (Cephalosporins) for 3 days followed by oral antibiotics for another 5 days

02. Suction drain removed after 24 hours

03. Active and passive physiotherapy of hip, knee and ankle started according to pain tolerance of patients.

04. $\mathrm{Hb} \%$, TC, DC and ESR was done on 2nd postoperative day and check dress on 3rd postoperative day (or as needed).

05 . Stitches removed after 12 days.

Depending upon the type of fracture and stability of fracture fixation, partial weight-bearing with support was started accordingly. For stable fractures, partial weigh bearing with walker support was allowed within 4 weeks. Unstable fractures and those 
Treated with primary bone grafting partial weightbearing was delayed up to 6 weeks. Full weightbearing was started after confirming sound healing of the fracture.

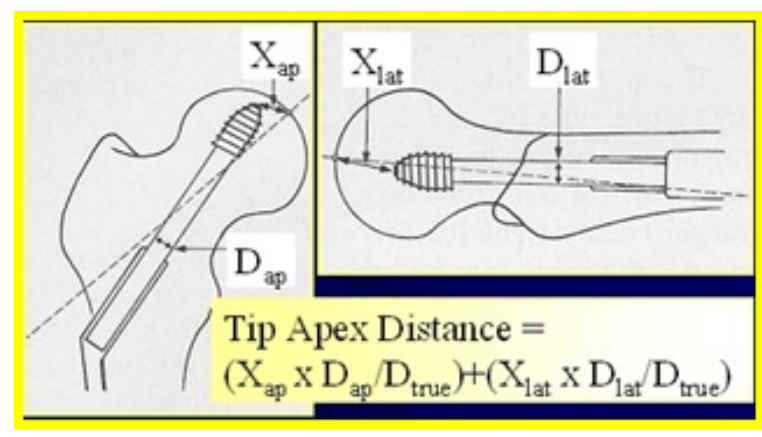

Fig-2: Assessment of screw position (implant placement).

In 1995 Baumgartner et al introduced the concept of the Tip-Apex Distance [5]. It describes the position of the screw within the head of the femur and was shown to be highly predictive of fixation failure by screw cut out regardless of other fracture variables. This measurement is the sum of the distance from the tip of the lag screw to the apex of the femoral head on an anteroposterior radiograph and this distance on a lateral radiograph, after controlling for magnification. If the x-rays were taken without magnification then the calculation of TAD index becomes simpler i.e. TAD = Xap + Xlat.

Measurement of lateral wall impaction/collapse: Lateral wall impaction measured after 6 months and correlated with functional outcome. Lateral wall impaction is directly proportional to sliding of the lag screw out of the barrel. Therefore if the screw has slide more out of barrel then it means there is more impaction. This can be measured by subtracting distance of screw thread from barrel tip in 6-month $x$-ray from a similar distance in immediate post-opx-ray.

If the distance of screw thread from barrel tip in 6 months post-op $\mathrm{x}$-ray is $\mathrm{B}$ and distance between screw thread and barrel tip is $A$ in immediate postopx-ray then distance through which screw has a slide $(C)$ is given by the formula: $C=A-B T h i s ~ C$ is directly proportional to lateral wall impaction(I). C= $\mathrm{pI}(\mathrm{p}$ is coefficient of proportion and it varies with neck-shaft angle). The two groups were compared for their functional outcome at each follow up with Modified Harris Hip score [6]. Impaction /collapse was measured in both groups at each follow-up and correlated with the functional outcome, with the aim to found the relation between two if there is any.
Statistical Analysis: Descriptive statistics such as mean, SD and percentage were used to present the data. Data analysis was performed by using Microsoft excel.

\section{Result}

Table -1: Age and Sex Incidence in both groups.

\begin{tabular}{|l|l|l|l|l|l|l|}
\hline \multirow{2}{*}{$\begin{array}{c}\text { Age group in } \\
\text { years }\end{array}$} & \multicolumn{2}{|c|}{$\begin{array}{c}\text { No. of the male } \\
\text { patient }\end{array}$} & \multicolumn{2}{|c|}{$\begin{array}{c}\text { No. of the female } \\
\text { patient }\end{array}$} & Total & \% \\
\cline { 2 - 6 } & Group A & Group B & Group A & Group B & & \\
\hline $20-40$ years. & 08 & 05 & 00 & 00 & 13 & 20 \\
\hline $41-60$ years. & 14 & 08 & 07 & 03 & 32 & 50 \\
\hline $61-80$ years. & 05 & 03 & 04 & 05 & 17 & 27 \\
\hline $80<$ years & 02 & 00 & 00 & 00 & 2 & 3 \\
\hline Total & 45 & 19 & 64 & 100 \\
\hline
\end{tabular}

Majority of the subjects belongs to age group 40-60 years.

Table -2:Type of fractures in patients according to Evan's classification.

\begin{tabular}{|c|l|l|l|c|}
\hline Group & Evan's grade & No. of patients & Total & $\%$ \\
\hline \multirow{3}{*}{ Group A } & I & 07 & 40 & 62.5 \\
\cline { 2 - 3 } & II & 17 & & \\
\cline { 2 - 3 } & IV & 16 & & \\
\hline \multirow{2}{*}{ Group B } & III & 14 & & \\
\cline { 2 - 3 } & V & 10 & & \\
\hline
\end{tabular}

Majority of the patients belongs to II grade (42.5\%) in group A whereas, in group $B$, the majority belongs to III grade (58.3\%).

Table-3:Reduction in different fracture groups.

\begin{tabular}{|l|l|l|l|l|l|l|}
\hline \multirow{4}{*}{ Reduction Achieved } & \multicolumn{5}{|c|}{ Fracture Groups } & \multicolumn{2}{c|}{ B B } \\
\cline { 2 - 7 } & \multicolumn{5}{|c|}{ A } & \\
\cline { 2 - 6 } & Grade I & Grade II & Grade IV & Grade III & Grade V & \\
\hline Anatomical Reduction & 07 & 16 & 10 & 06 & 02 & 41 \\
\hline Anatomical alignment & 00 & 01 & 06 & 08 & 08 & 23 \\
\hline Total & 07 & 17 & 16 & 14 & 10 & 64 \\
\hline
\end{tabular}

Table-4: Impaction achieved at fracture site after 6 months.

\begin{tabular}{|l|l|l|l|l|l|l|l|l|l|l|l|l|}
\hline \multicolumn{1}{|c|}{} & \multicolumn{10}{|c|}{ Impaction measured in mm } \\
\cline { 2 - 11 } & & $2-4$ & $4-6$ & $6-8$ & $8-10$ & $10-12$ & $12-14$ & $12-16$ & $16-18$ & $18-20$ & $20-22$ & $22-24$ \\
\hline \multirow{6}{*}{ Group A } & I & 07 & 00 & 00 & 00 & 00 & 00 & 00 & 00 & 00 & 00 & 00 \\
\cline { 2 - 11 } & II & 10 & 05 & 01 & 01 & 00 & 00 & 00 & 00 & 00 & 00 & 00 \\
\cline { 2 - 11 } & IV & 02 & 06 & 05 & 03 & 00 & 00 & 00 & 00 & 00 & 00 & 00 \\
\hline Group B & III & 00 & 01 & 02 & 02 & 03 & 02 & 03 & 01 & 00 & 00 & 00 \\
\cline { 2 - 11 } & V & 00 & 00 & 00 & 00 & 00 & 03 & 02 & 01 & 02 & 01 & 01 \\
\hline Total & 19 & 12 & 08 & 06 & 03 & 05 & 05 & 02 & 02 & 01 & 01 \\
\hline
\end{tabular}

Anatomical reduction mostly observed grade II in group A whereas, in group B, anatomical alignment 
Was observed by grade III and V.

In the present study, it was observed that impaction achieved better in group $A$ than group $B$

Table- 5:Type of plate used- long or short barrel.

\begin{tabular}{|l|l|l|l|l|l|l|}
\hline \multirow{1}{*}{ Type of plate used } & \multicolumn{5}{c|}{ Lag screw length in mm } & \multirow{2}{*}{ Total } \\
\cline { 2 - 7 } & 80 & 85 & 90 & 95 & 100 & \\
\hline Long barrel & 00 & 10 & 25 & 08 & 03 & 46 \\
\hline Short barrel & 08 & 10 & 00 & 00 & 00 & 18 \\
\hline Total & 08 & 20 & 25 & 08 & 03 & 64 \\
\hline
\end{tabular}

Most of the plate used in the present study was a long barrel with lag screw length $85 \mathrm{~mm}$ and 90 $\mathrm{mm}$.

Table:6:Functional Results in various fracture grades.

\begin{tabular}{|l|l|l|l|l|l|l|}
\hline \multirow{2}{*}{ Group } & \multirow{2}{*}{ Grades } & \multicolumn{3}{|c|}{ Functional Results } & \multirow{2}{*}{ Total } \\
\cline { 3 - 6 } & & Excellent & Good & Fair & Poor & \\
\hline \multirow{3}{*}{ Group A } & I & 06 & 01 & 00 & 00 & 07 \\
\cline { 2 - 6 } & II & 10 & 05 & 02 & 00 & 17 \\
\cline { 2 - 6 } & IV & 04 & 08 & 04 & 00 & 16 \\
\hline \multirow{3}{*}{ Group B } & III & 02 & 03 & 08 & 01 & 14 \\
\cline { 2 - 6 } & V & 00 & 03 & 06 & 01 & 10 \\
\hline Total & 22 & 20 & 20 & 02 & 64 \\
\hline
\end{tabular}

It was observed that the functional outcome was better seen in group $A$ than group $B$.

\section{Discussion}

Management of Trochanteric fractures has always posed a challenge to the Orthopaedic surgeon because of the multitude of complications abound in the senile patients with the fracture. Therefore it involves a multidisciplinary approach. Hence there are multiple factors affecting functional outcome in these patients, and still, existing factors are not sufficient to predict the prognosis.

A total of 64 cases of trochanteric fractures treated by Dynamic hip screw fixation were followed in the study for 6 months. The age of patients varied from 22 yrs to 88 yrs. $70 \%$ of patients were younger than $60 \mathrm{yrs}$. The average age of the patient in this series was 55 yrs, which is significantly lower as compared to various studies published i.e. Parker 71.5 yrs [7], Bhatti - 71 yrs [8].

The frequency of trochanteric fractures in relatively younger age group in this series may be related to the shorter life expectancy of the population and high-velocity trauma causing the fracture in several younger patients in the study.
Sperner showed that postoperative complicationsare caused by early full weight-bearing, which leads to varus and recurvation malposition [9], but Larson, Frieberg in their showed that postoperatively, the neck-shaft angle decreased more in unstable fractures than in stable fractures. The decrease in the neck-shaft angle was less when the proximal fragment impinged medially on the shaft fragment. Unstable fractures with this type of reduction also impacted less than hips with anatomic reduction or medial reduction of the shaft fragment. Weightbearing did not significantly influence the degree of impaction [10]. In the current study, no specific protocols regarding weight-bearing were followed and all cases where special reduction techniques were followed were excluded from the study. This study showed that $65 \%$ fractures were unstable [10], on the contrary in the current study only $37.5 \%$ fractures were unstable.Parker $\mathrm{MJ}$ showed that cutting out of dynamic hip screw was related to its position. He concluded that central placement for better results than any other location. Although a slight inferior location on the frontal plane was acceptable, superior placement should always be avoided [7].

Galankis showed that central placement of the sliding screw resulted in the decreased mean value of migration of implant [11].

Beumgaertner $M$, Curtin $S$, LindskogD and KeggiJMconcluded that TAD index less than $25 \mathrm{~mm}$ reduced the chance of cutout to large extent and there is strong statically relationship between increasing Tip-Apex Distance and the rate of the cutout, regardless of all other variables related to fracture [12]. Banmgaertner $M$ and Solberg concluded that awareness of TAD index reduces the failure of the fixation of two fractures of the hip. In their study, they attempted to decreased the mean TAD index value to less than $20 \mathrm{~mm}$ and thereby mechanical failure almost dropped to zero confirming the importance of good surgical technique [13]. In 2004,Pervez H, Parker MJ and Vowlers in their milestone study concluded that no. of the technical aspect of sliding hip screw fixation affect the final functional outcome. The TAD index with correction for magnification was found to show the most significant difference between patients with cutout against those without $(p=0.001)$, followed by the lag screw position on the lateral radiographic reduction of fracture on the anteriorposterior radiograph and the uncorrected TAD index [14]. In the current study, all the cases with TAD 
Index more than $25 \mathrm{~mm}$ were excluded to avoid postoperative failure to be included in the study and to avoid the effect of implant placement over the postoperative functional outcome. Rha JD et. al showed that complications were only found in unstable fractures. They occurred most frequently in elderly patients and when the distal fragment was displaced medially and anteriorly [15]. In the current study sliding of implant and impaction was found to be more in an unstable group which is according to this study by Rha JD et al. Parker showed the importance of angle of reduction in post-op results [7]. In the current study, only those cases with a neck-shaft angle 130 to 140 degree were included. This eliminated important confounding factor for comparison of functional outcome in both groups. Nakala K. et. alfound that there was a significant correlation between the extent of sliding at union and healing time. The average healing time in group $B$ (The extent of sliding at the union of $8 \mathrm{~mm}$ or greater) was 138 weeks postoperatively and that in group $A$ (the extent of sliding at the union of less than $8 \mathrm{~mm}$ ) was 89 weeks. The phenomenon of sliding progressed mainly during the first 2 weeks postoperatively. There was a significant positive correlation between the extent of sliding at union and the extent of sliding at 2 weeks postoperatively. An assessment using the extent of sliding at 2 weeks postoperatively can accurately predict the extent of sliding at union and healing time. It is important to examine the phenomenon of sliding during the early postoperatively course, especially until 2 weeks postoperatively in order to predict fracture repair [16]. In the current study time at which union started is average 9.5 weeks in the stable group and average impaction in this group was $5.5 \mathrm{~mm}$. In an unstable group average time at which union started was 12.5 weeks and average impaction was $14 \mathrm{~mm}$. In 2005, Templeman, Baumgaertn, Leightonet al. in their landmark tutorial article stated that "the increasing number of hip fractures in the elderly constitutes a health care burden. The subset of unstable intertrochanteric hip fractures is important because the treatment of these fractures continues to be hampered by a moderate complication rate. Osteoporosis, fracture geometry, and the success of surgical treatment are strong predictors of outcome. The surgeon in control of fracture reduction, implant selection, and implant placement, all of which must be optimized to ensure the success of surgical intervention? [17]. Joseph, Thomas $N$, et al in their study evaluated the effects of posterior sag on the
Fixation stability of intertrochanteric hip fractures and found that 30 degrees of posterior sag do not result in a significant difference in construct strength or stability [18]. In the treatment of unstable intertrochanteric fractures of the femur, whether the continuity of posteromedial cortex or the structural buttress by a greater trochanter is intact are thought to be a critical factor to determine the stability. The current study showed that this structural buttress is not present in lateral trochanteric wall fracture, this leads to greater impaction and poor functional outcome.

\section{Limitations}

Further study in a large number of patients is required to comment regarding disadvantages and complications.

\section{Conclusion}

From the present study, it was concluded that intact lateral trochanteric wall helps in achieving anatomical reduction, imparts inherent stability and prevents excessive collapse, limb shortening and sliding of the screw. Thus it helps in achieving good functional outcome making lateral trochanteric wall fracture good predictor of functional outcome.

\section{What does the study add to the existing knowledge?}

Literature on functional outcome of DHS in trochanteric fractures has shown almost neglects other important potential prognostic factor i.e. lateral trochanteric wall fracture which makes meaningful adding in the existing literature by conducting the current study to timely recognition and understanding of common factors related to trochanteric fracture.

\section{Author's contribution}

Dr. Santosh Deshpande: Study design, concept

Dr. Saurabh R. Agrawal: Manuscript preparation

\section{Reference}

01. Bhatti A, Power D, Qureshi S, Khan I, Tan S. A prospective trial of proximal femoral nail versus dynamic hip screw for unstable and complex intertrochanteric fractures of the femur. J Bone Joint Surg. 2004;8;377-377.

[Crossref] 
02. McLoughlin SW, Wheeler DL, Rider J, Bolhofner B. Biomechanical evaluation of the dynamic hip screw with two- and four-hole side plates. J Orthop Trauma. 2000;14(5)318-323.

doi:[Article:https://doi.org/10.1097/00005131-2000 06000-00002][Crossref]

03. Schumpelick W. A new principle in the operative treatment of trochanteric and Jantzen PM fracture of the femur. J Bone Surg. $1955 ; 37 A(4) 693-698$.

[Crossref]

04. Mulholland RC, Hunn DR. Sliding screw plate fixation of intertrochanteric femoral fracture. J Trauma. 1972;12(7)581-591.

doi:[Article:https://doi.org/10.1097/00005373-1972 07000-00006][Crossref]

05. Li S, Chang SM, Jin YM, Zhang YQ, Niu WX, Du $\mathrm{SC}$, et al. A mathematical simulation of the tipapex distance and the calcar-referenced tipapex distance for intertrochanteric fractures reduced with lag screws. Injury. 2016;47(6)1302-1308.

doi:[Article:https://doi.org/10.1016/j.injury.2016.03. 029][Crossref]

06. Jewett EL. One-piece angle nail for trochanteric fractures. J Bone Joint Surg. 1941;23(4)803810.

[Crossref]

07. Sperner G, Wanitschek P, Benedetto KP, Glotzer W. Technical errors and early complications of osteosynthesis of pertrochanteric femoral fractures using the dynamic hip screw. Unfallchirurg. 1989;92(12):571-576.

[Crossref]

08. Baumgaertner M, Curtin S, Lindskog D, Keggi J $M$. The value of the tip apex distance in predicting failure of fixation. J Bone Joint Surg Am. $1995 ; 77(7) 1058-1064$.

doi:[Article:https://doi.org/10.2106/00004623-1995 07000-00012][Crossref]

09. Hanis H. Harris Hip Score. J Bone Joint Surg Am. 1969;5 I-A (4)737-755.

[Crossref]

10. Baumgaertner M, Solberg BD. Awareness of tipapex distance reduces failure of fixation of trochanteric fractures of the hip. J Bone Joint Surg Br. 1997;79(6)969-971.

doi:[Article:https://doi.org/10.1302/0301-

620x.79b6.7949][Crossref]
11. Galanakis IA, Steriopoulos KA, Dretakis EK. Correct placement of the screw or nail in trochanteric fractures, Effect of the initial placement in the migration. Clin OrthopRelat Res. 1995;(313)206-213.

[Crossref]

12. Parker MJ. Valgus reduction of trochanteric fractures. Injury. 1993;24(5)313-316. doi:[Article:https://doi.org/10.1016/0020-1383 (93)90053-9][Crossref]

13. Larsson S, Friberg S, Hansson LI. Trochanteric fractures. Influence of reduction and implant position on impaction and complications. Clin OrthopRelat Res. 1990;(259)130-139 [Crossref]

14. Pervez H, Parker MJ, Vowler S. Prediction of fixation failure after sliding hip screw fixation. Injury. 2004;35(10)994-998.

doi:[Article:https://doi.org/10.1016/j.injury.2003. 10.028][Crossref]

15. Rha JD, Kim YH, Yoon SI, Perk YS, Lee MH. Factors affecting sliding of the leg screw in intertrochanteric fractures. Int Orthop. 1993;17(S)320-324.

doi: [Article:https://doi.org/10.1007/bf00181709] [Crossref]

16. Joseph TN, Chen AL, Kummer FJ, Koval KJ. The effect of posterior sag on the fixation stability of intertrochanteric hip fractures. J Trauma Acute Care Surg. 2002;52(3)544-547.

doi:[Article:https://doi.org/10.1097/00005373-2002 03000-00021][Crossref]

17. Templeman D, Baumgaertner MR, Leighton RK, Lindsey RW, Moed BR. Reducing complications in the surgical treatment of intertrochanteric fractures. Instr Course Lect. 2005;54;409-415. [Crossref]

18. Nakata K, Ohzono K, Hiroshima K, Toge K. Serial change of sliding in intertrochanteric femoral fractures treated with sliding screw system. Arch Orthop Trauma Surg. 1994;113(5)276-280.

doi: [Article:https://doi.org/10.1007/bf00443817] [Crossref] 